\title{
CAPACITY BUILDING ORGANISASI (STUDI PADA KELURAHAN IMOPURO KECAMATAN METRO PUSAT KOTA METRO)
}

\author{
Mirnawati \\ STISIPOL Dharma Wacana Metro \\ mirnaheru5@gmail.com
}

Diterima: 02 Maret 2019 Disetujui: 17 Juni 2019 Dipublikasikan: 25 Juni 2019

\begin{abstract}
The struggle to achieve the creation of good governance is the hard effort of the existence of the current government in overcoming all problems. The government organization of Imopuro urban village of metro Pusat. subdistrict of Metro city in the effort to overcome the problems such as eliminating the predicate of slum and densest populations also in order to make the people prosperous, capacity building efforts through individual/human resources development, organizational/institutional development and management system development. The purpose of this research is to know how capacity building organization in Imopuro, Imopuro subdistrict, Metro city focused on individual/human resources level, organization level and management system level. The method used with qualitative approach descriptive type to see the development before and after research. Data collection techniques were conducted through interviews, observation and documentation. The results of this research can be seen that in general the capasity of the organization is focused on the level of individual/human resources, the level of organization/institution and the level of the system in the Imopuro, metro, Yosomulyo, Hadimulyo West, Hadimulyo East, capasity building of the organization especially at the level of individual that is increase of knowledge, ability and effort to change attitude of employee or mainset in work through training or supplementary education, in organizational stay that is repair and completeness of
\end{abstract}




\title{
Mirnawati: CAPACITY BUILDING ORGANISASI;
}

supporting facilities and infrastructure and addition fund operational budget, the main tasks and functions of the work unit should be in accordance with the quality and educational background and fill the vacancy of employees in every field.

\section{Keywords: Capacity Building, Organization.}

\begin{abstract}
Abstrak
Perjuangan untuk mencapai penciptaan pemerintahan yang baik adalah upaya keras dari keberadaan pemerintah saat ini dalam mengatasi semua masalah. Organisasi pemerintah desa perkotaan Imopuro metro Pusat. Kecamatan kota Metro dalam upaya mengatasi masalah seperti menghilangkan predikat kumuh dan populasi terpadat juga dalam rangka menjadikan masyarakat sejahtera, upaya peningkatan kapasitas melalui pengembangan individu / sumber daya manusia, pengembangan organisasi/kelembagaan dan pengembangan sistem manajemen. Tujuan dari penelitian ini adalah untuk mengetahui bagaimana organisasi pengembangan kapasitas di Imopuro, Kecamatan Imopuro, Kota Metro difokuskan pada level individu/sumber daya manusia, level organisasi dan level sistem manajemen. Metode yang digunakan dengan pendekatan kualitatif tipe deskriptif untuk melihat perkembangan sebelum dan sesudah penelitian. Teknik pengumpulan data dilakukan melalui wawancara, observasi dan dokumentasi. Hasil penelitian ini dapat dilihat bahwa secara umum kapasitas organisasi difokuskan pada tingkat individu/sumber daya manusia, tingkat organisasi/lembaga dan tingkat sistem di Imopuro, metro, Yosomulyo, Hadimulyo Barat, Hadimulyo Timur, pengembangan kapasitas organisasi terutama pada tingkat individu yaitu peningkatan pengetahuan, kemampuan dan upaya untuk mengubah sikap karyawan atau mainset dalam pekerjaan melalui pelatihan atau pendidikan tambahan, dalam masa tinggal organisasional yaitu perbaikan dan kelengkapan sarana dan prasarana pendukung dan penambahan anggaran operasional dana, tugas dan
\end{abstract}




\section{Mirnawati: CAPACITY BUILDING ORGANISASI;}

fungsi utama unit kerja harus sesuai dengan kualitas dan latar belakang pendidikan dan mengisi kekosongan karyawan di setiap bidang.

\section{Kata kunci: Pengembangan Kapasitas, Organisasi.}

\section{PENDAHULUAN}

Indonesia adalah salah satu negara di dunia yang memiliki mimpi dan harapan mendapat predikat Good Governance. Predikat tidak semata-mata didapat begitu saja melainkan perlu usaha maksimal untuk mencapainya.Terdapat fenomena-fenomena yang menyebabkan good governace sulit dicapai salah satunya adalah kemiskinan dan keterbelakangan, mudah terpecah belah serta tidak berfikir produktif. Fakta soal kemiskinan yang disebutkan diperkuat dari hasil penelitian lapangan Bappeda mengenai survei sosial ekonomi rumah tangga dibeberapa kota/kabupaten di Indonesia salah satunya adalah Kota Metro yang menyatakan dari berapa kecamatan dan kelurahan di Kota Metro terdapat kelurahan yang di kategorikan penduduk terpadat dan terkumuh.

Menghadapi permasalahan diatas dan untuk mencapai eksistensi pemerintah dalam memperbaiki dan membenahi tentu saja membutuhkan pemerintahan Kelurahan yang tangguh yaitu pemerintahan yang siap bersaing dan mampu menghadapi permasalahan yang akan terjadi baik di tingkat individu/sumber daya manusia, tingkat organisasi/lembaga dan tingkat sistem ketatalaksanaan agar pemerintahan kelurahan mampu memenuhi tuntutan masyarakat dan merespon masalah masalah warganya, pemerintah menjadi tanggap supaya masyarakat tidak merasa kecewa dan tidak meragukan integritas pemerintahan yang ada. Menghadapi beberapa permasalahan tersebut diatas diperlukan pengembangan kapasitas (Capacity Building). Capacity building kelembagaan pemerintah dapat diartikan sebagai upaya membangun organisasi, sistem-sistem, kemitraan, orang-orang dan proses-proses secara benar untuk menjalankan agenda atau rencana tertentu. Pengertian capacity 
building memberikan gambaran bahwasanya terdapat banyak hal yang harus diperhatikan dan dicermati secara jeli agar capacity building dapat membuahkan hasil nyata, bermanfaat, dan menimbulkan dampak positif. Menurut Brown, pengembangan kapasitas merupakan suatu proses yang dapat meningkatkan kemampuan seseorang, organisasi atau sistem untuk mencapai tujuan yang hendak dicapai.

Capacity building lebih khusus dalam bidang kepemerintahan dijelaskan Yeremias T. Keban bahwa capacity building merupakan serangkaian strategi yang ditujukan untuk meningkatkan efisiensi, efektivitas, dan responsivitas dari kinerja pemerintahan, dengan memusatkan perhatian pada pengembangan dimensi, sumber daya manusia, penguatan organisasi, dan reformasi kelembagaan atau lingkungan. Capacity building sebagai alat aksi untuk menuju ke dalam sistem kepemerintahan yang baik sebenarnya berhubungan dengan upaya meminimalisir peran (role) dan cakupan pemerintahan. ${ }^{2}$ Sebagai ujung tanduk pemrintahan paling terendah kelurahan Imopuro kecamatan Metro Pusat mendapat predikat daerah terkumuh dan penduduk terpadat di Kota Metro, untuk itu perlu penanganan.

Kesimpulan dari persoalan-persoalan yang diuraikan diatas dalam penelitian ini dimaksudkan untuk mengetahui upaya pemerintah Kelurahan Imopuro dalam menanggulangi persoalan, menghilangkan predikat kumuh, mengurangi kepadatan penduduk serta mensejahterakan masyarakatnya melalui capasity building organisasi kelurahan yang meliputi pengembangan individu/SDM, pengembangan organisasi/lembaga, pengembangan sistem ketatalaksanaan dengan tujuan akhir mencapai Good Governance. Berdasarkan latar belakang masalah, maka penulis dapat merumuskan permasalahan yaitu, mengenai capacity building organisasi di

${ }^{1}$ Lisanne, Measuring Capacity Building (Carolina: University of North Carolina: Carolina population Center Chapel Hill, 2001), 2001), h 8.

${ }^{2}$ Riyadi Soeprapto, "Banking Assets and Liability Management," Banking Assets and Liability Management, Edsi Ketiga, (Jakarta: Penerbit Fakultas Ekonomi Universitas Indonesia, 2006), 2006, h 7. 


\section{Mirnawati: CAPACITY BUILDING ORGANISASI;}

Kelurahan Imopuro Kecamatan Metro Pusat Kota Metro pada tingkatan individu/SDM, tingkatan organisasi/lembaga dan tingkatan sistem ketatalaksanaan.

\section{TINJAUAN PUSTAKA Capacity Building}

Merilee S. Grindle (1997:23) menyebutkan capacity building merupakan upaya yang ditunjukan untuk mengembangkan suatu strategi guna meningkatkan efisiensi, efektifitas, dan responsivitas kinerja pemerintah. Efisiensi disini dalam hal waktu dan sumber daya yang dibutuhkan untuk mencapai mencapai outcome, efisiensi berupa kepantasan usaha yang dilakukan demi hasil yang diinginkan serta responsivitas bagaimana menyesuaikan antara kebutuhan dan kemampuan untuk maksud tersebut. Definisi lain tentang capacity buildingyang dikemukakan oleh Morisson (2001:42) yaitu melihat capacity building sebagai suatu proses untuk melaksanakan sesuatu, atau serangkaian gerakan, perubahan multi level di dalam individu, kelompok-kelompok, organisasi-organisasi dan sistem-sistem dalam rangka untuk memperkuat kemampuan penyesuaian individu dan organisasi sehingga dapat tanggap terhadap perubahan lingkungan yang ada. ${ }^{3}$

Penjelasan Grindle ${ }^{4}$ sudah cukup jelas bahwa tingkaan dari capacity bilding terdiri atas (1) Pengembangan sumber daya manusia, (2) penguatan organisasi dan (3) reformasi kelembagaan. Dari beberapa uraian mengenai capacity building tersebut di atas, akan dapat dikemukakan tingkatan-tingkatan dalam penembangan kapasitas

\footnotetext{
${ }^{3}$ Morrison T, Actionable Learning -A Handbook for Capacity Building Through Case Based Learning. (ADB Institute, 2001, t.t.), h 42.

${ }^{4}$ M.S Grindle, Getting Good Government Capacity Building In The Public Sector Of Developing Countrie, (Boston: MA: Harvard Institute for International Development, 1997), 1997).
} 


\section{Mirnawati: CAPACITY BUILDING ORGANISASI;}

yang harus dilaksanakan secara berkesinambungan yang terdiri dari 3 (tiga) tingkatan menurut Mowbray, ${ }^{5}$ terdiri dari:

1. Tingkatan dan Dimensi Individu, adalah tingkatan dalam sistem yang paling kecil, dalam tingkatan ini. Aktivitas capacity building yang ditekankan ada aspek memberi pembelajaran kepada individu dalam rangka mendapatkan sumber daya manusia yang berkualitas dalam ruang llingkup penciptaan peningkatan ketrampilan-ketrampilan dalam diri individu, penambahan pengetahuan dan teknologi yang berkembang saat ini, peningkatan tngkah laku untuk memberikan tauladan dan motivasi

2. Tingkatan dan Dimensi pengembangan kapasitas pada kelembagaan atau organsasi terdiri dari sumber daya organisasi, budaya organisasi, ketatalaksanaan, struktur organisasi atau sistem pengambilan keputusan.

3. Tingkatan dan dimensi pengembangan kapasitas pada sistem merupakan tingkatan yang paling tinggi dimana seluruh komponen masuk didalamnya. Tingkatan sistem, seperti kerangka kerja yang berhubungan dengan pengaturan, kebijakan-kebijakan dan kondisi dasar yang mendukung pencapaian obyektivitas kebijakan tertentu.

\section{Tingkatan Individu/SDM}

Individu merupakan salah satu komponen yang penting dalam suatu organisasi mencapai tujuan dari organisasi. Pencapaian tersebut akan terpenuhi dengan adanya daya dukung dari tingkat pengetahuan tingkat keterampilan serta sikap dan perilaku kerja yang dimiliki oleh setiap pegawai. Pengetahuan (Knowledge), Keterampilan (Skill), dan Sikap (Attitude).Menurut Anelli Milen, pengertian mengenai karakteristik dari pengembangan kapasitas adalah sebuah proses peningkatan secara terus menerus (berkelanjutan) dari setiap individu, organisasi atau institusi, dan tidak hanya terjadi satu kali.

${ }^{5}$ M Mowbray, "Community Capacity Building or State Opportunism?," Community Capacity Building or State Opportunism?. Community Development Journal, 40(3), 2005, h. 255-264. 


\section{Mirnawati: CAPACITY BUILDING ORGANISASI;}

Notoatmodjo mengemukakan pengetahuan adalah hasil penginderaan manusia atau hasil tahu seseorang terhadap objek melalui indera yang dimilikinya sehingga menghasilkan pengetahuan.Faktor yang mempengaruhi pengetahuan: ${ }^{6}$

a. Sosial ekonomi Lingkungan sosial akan mendukung tingginya pengetahuan seseorang,

b. Kultur (budaya,agama) Budaya sangat berpengaruh terhadap tingkat pengetahuan seseorang.

c. Pendidikan Semakin tinggi pendidikan maka ia akan mudah menerima hal-hal baru

d. Pengalaman Berkaitan dengan umur dan lama bekerja. yaitu: ${ }^{7}$

Menurut Robbins keterampilan dibagi menjadi 4 kategori

1. Basic Literacy Skill: Keahlian dasar yang sudah pasti harus dimiliki oleh setiap orang seperti membaca, menulis, berhitung serta mendengarkan.

2. Technical Skill: Keahlian secara teknis yang didapat melalui pembelajaran dalam bidang teknik seperti mengoperasikan komputer dan alat digital lainnya

3. Interpersonal Skill: Keahlian setiap orang dalam melakukan komunikasi satu sama lain

4. Problem Solving: Keahlian seseorang dalam memecahkan masalah dengan menggunakan logikanya.

Menurut para tokoh dalam Aisyah Tyasmaharani (2016):

1. Gibson (1997), menjelaskan sikap sebagai perasaan positif atau negatif atau keadaan mental yang selalu disiapkan, dipelajari dan diatur melalui pengalaman yang memberikan pengaruh khusus pada respon seseorang terhadap orang, obyek ataupun keadaan. Sikap lebih merupakan determinan perilaku sebab, sikap berkaitan dengan persepsi, kepribadian dan motivasi.

${ }^{6}$ S Notoatmodjo, Promosi Kesehatan dan Ilmu Perilaku (Jakarta: Rineka Cipta, 2007), h 140.

${ }^{7}$ Robbins, Keterampilan Dasar (Jakarta: PT. Raja Grafindo, 2000). 
2. Sada (2000), adalah tindakan yang akan diambil karyawan dan segala sesuatu yang harus dilakukan karyawan tersebut yang hasilnya sebanding dengan usaha yang dilakukan.

Kepuasan kerja merupakan salah satu faktor yang sangat penting untuk mendapatkan hasil kerja yang optimal. Ketika seorang merasakan kepuasan dalam bekerja tentunya ia akan berupaya semaksimal mungkin dengan segenap kemampuan yang dimilikinya untuk menyelesaikan tugas pekerjaannya. Dengan demikian produktivitas dan hasil kerja karyawan akan meningkat secara optimal. Sikap kerja dapat diukur dengan:

a. Kerja ikhlas

Sikap kerja prestatif yang pertama adalah kerja ikhlas, maksud dari kerja ikhlas adalah bekerja dengan bersungguh-sungguh, semangat, dan tidak mengeluh sehingga dapat memperoleh hasil yang maksimal, kerja ikhlas juga dilandasi dengan hari yang tulus.

b. Kerja mawas terhadap emosional

Sikap kerja prestatif yang kedua adalah pengertian mawas terhadap emosional, maksud dari kerja mawas terhadap emosional adalah bekerja dengan sebaik-baiknya tanpa terpengaruhi oleh perasaan/emosional yang sedang melanda jiwanya. Dengan kata lain seorang pengusaha atau pekerja harus dapat memisahkan urusan pribadi dengan urusan pekerjaanya, jangan sampai urusan pribadinya mengganggu pekerjaannya yang dapat berakibat tidak baik bagi perusahaan atau usaha yang dijalaninya.

c. Kerja cerdas

Setelah memahami kerja ikhlas dan mawas terhadap emosional, sikap kerja prestatif yang ketiga adalah kerja cerdas. Maksud dari kerja cerdas ini adalah bekerja pandai untuk memperhitungkan risiko (tidak mengabaikan risiko, dan memikirkan besar-kecilnya risiko yang akan didapat), mampu melihat dan memanfaatkan peluang yang ada, serta dapat mencari solusi ketika terjadi suatu masalah dalam pekerjaan atau usahanya.

d. Kerja keras 
Sikap kerja prestatif yang ke-empat adalah kerja keras, maksud dari kerja keras adalah bekerja dengan bersungguh-sungguh, tidak mudah menyerah, tidak mengeluh, tidak membuang-buang waktu, dan memanfaatkan waktu dengan sebaik-baiknya (efektif dan optimal).

e. Kerja tuntas

Maksud dari kerja tuntas ini adalah bekerja secara tuntas, tidak setengah-setengan, selain itu juga dalam bekerja mampu mengorganisasikan bagian usahanya secara terpadu dari awal sampai akhir untuk dapat memperoleh hasil yang baik.

\section{Tingkatan Organisasi/Lembaga}

Pengembangan kapasitas kelembagaan terdapat enam fokus yakni, struktur organisasi, mekanisme kerja, budaya organisasi, sistem anggaran/nilai, sarana prasarana dan prosedur kerja. Dalam penelitian ini peneliti hanya memfokuskan pada 3 (tiga) saja yaitu:

1. Struktur Organisasi

2. Sistem Anggaran

3. sarana prasarana

Robbins $^{8}$ mengatakan bahwa struktur organisasi bertujuan untuk menetapkan bagaimana tugas dan pekerjaan dibagi, dikelompokkan dan dikoordinasikan.AIDSTAR-Two. (2011)

1. Organisasi harus memiliki kebijakan yang jelas dan lengkap serta memiliki kearsipan yang baik.

2. Sistem perekrutan yang jelas

3. Adanya penilaian kinerja pegawai yang baik.

Peraturan Pemerintah No.52 Tahun 2012 tentang kerangka Nasional Pengembangan Kapasitas Pemerintah daerah Pasal 20 ayat 2 bahwa program dan kegiatan pemerintahan daerah dibebankan pada anggaran dan peendapatan belanja pemerintah daerah masingmasing.Teori World Bank yang menekankan perhatian capacity

${ }^{8} \mathrm{~h} 6$. 
bulding pada fokus lingkungan organisasi yang mengarah pada dukungan keuangan dan anggaran dalam merealisasi seluruh kegiatan dan kebutuhan organisasi. Moenir, ${ }^{9}$ menjelaskan sarana dan prasarana adalah segala jenis peralatan, perlengkapan kerja dan fasilitas yang berfungsi sebagai alat utama/pembantu dalam pelaksanaan pekerjaan, dan juga dalam rangka kepentingan yang sedang berhubungan dengan organisasi kerja.

Moenir juga membagi sarana dan prasarana menjadi 3 yakni:

1. Peralatan kerja, yaitu semua jenis benda yang berfungsi langsung sebagai alat produksi untuk menghasilkan barang atau berfungsi memproses suatu barang yang berlainan fungsi dan gunanya.

2. Perlengkapan kerja, yaitu semua jenis benda yang berfungsi sebagai alat pembantu tidak langsung dalam produksi, mempercepat proses, membangkit dan menambah kenyamanan dalam pekerjaan.

3. Perlengkapan bantu atau fasilitas, yaitu semua jenis benda yang berfungsi membantu kelancaran gerak dalam pekerjaan, misalnya mesin ketik, mesin pendingin ruangan, mesin absensi, dan mesin pembangkit tenaga.

\section{Tingkatan Sistem/Ketatalaksanaan}

Tingkatan sistem /ketataksanaan diukur dari kapasitas penerapan standar operasional operasi, kapasitas kepemimpinan dan kapasitas tupoksi unit kerja.Dalam penyelenggaraan tugas- tugas pemerintah daerah harus menyesuaikan dengan Standar Operasional Prosedur (SOP) adalah sebuah petunjuk buku yang sifatnya tertulis. SOP menurut pandangan Tambunan adalah pedoman yang berisi prosedur-prosedur operasional yang ada dalam suatu organisasi yang digunakan untuk memastikan, bahwa semua keputusan dan tindakan serta penggunaan fasilitasfasilitas proses yang dilakukan oleh orang-

${ }^{9}$ A.S Moenir, Manajemen Pelayanan Umum di Indonesia, (Jakarta: Bumi Aksara, 1992), h 119. 


\section{Mirnawati: CAPACITY BUILDING ORGANISASI;}

orang di dalam organisasi berjalan secara efektif, konsisten, standard dan sistematis. ${ }^{10}$

Salah satu hal yang mendukung proses capacity building organisasi berjalan dengan baikadalah dengan adanya kepemimpinan yang berjalan sesuai dengan visi dan misi awal yang diusung. Pemimpin memainkan peran yang penting dalam membantu organisasi untuk mencapai sebuah tujuan yang telah disepakati bersama.Keith Davis menyimpulkan, ada empat ciri atau sifat pemimpin yang dapat menyebabkan keberhasilan dalam memimpin, yaitu:

1. Intelegensia yang berarti, para pemimpin pada umumnya relatif lebih cerdas dari rata-rata pengikutnya

2. Mempunyai motivasi dan keinginan berprestasi dari dalam, artinya bahwa pemimpin umumnya mempunyai dorongan yang besar untuk dapat menyelesaikan sesuatu

3. Kematangan dan keluasan pandangan sosial, artinya bahwa secara emosi pemimpin pada umumnya selalu matang, sehingga mampu mengendalikan keadaan yang kritis. Mereka umumnya juga mempunyai keyakinan dan kepercayaan pada diri sendiri

4. Mempunyai kemampuan mengadakan hubungan antar manusia, artinya pemimpin itu tahu bahwa untuk mencapai sesuatu mereka amat tergantung den- gan orang lain, oleh sebab itu mereka selalu ingin dapat mengerti dengan orang lain. Mereka berorientasi kepada bawahan.

Tugas Pokok dan fungsi merupakan salah satu faktor pendukung proses capacity buiding organisasi agar berjalan dengan baikadalah dengan adanya pembagian tugas yang jelas tertata dan tersusun mampu membantu organisasi mencapai tujuannya. Tugas Pokok dan Fungsi (TUPOKSI) Kelurahan Imopuro adalah sesuai

${ }^{10}$ Rudi M. Tambunan, Standard Operating Prosedures (SOP) (Jakarta:

Maiestas Publishing, 2008), h 79.

${ }^{11}$ Keith Davis, ,Human Behavior at Work: Human Relations and Organizational Behavior, Fourth Edition, (New York: McGraw-Hill, 1972). 


\section{Mirnawati: CAPACITY BUILDING ORGANISASI;}

dengan Peraturan Daerah Kota Metro Nomor 03 Tahun 2003 Tentang Organisasi dan Tata Kerja Kecamatan dan Kelurahan Kota Metro.

\section{Organisasi}

Terdapat beberapa teori dan perspektif mengenai organisasi, ada yang cocok satu sama lain, dan ada pula yang berbeda. Organisasi pada dasarnya digunakan sebagai tempat atau wadah bagi orang-orang untuk berkumpul, bekerja sama secara rasional dan sistematis, terencana, terpimpin dan terkendali, dalam memanfaatkan sumber daya (uang, material, mesin, metode, lingkungan), sarana-parasarana, data, dan lain sebagainya yang digunakan secara efisien dan efektif untuk mencapai tujuan organisasi.

Pengertian Organisasi Publik Menurut Nutt dan Backof istilah publik berasal dari bahasa Latin "of people" (yang berkenaan dengan masyarakat).Sasaran organisasi publik ditujukan kepada masyarakat umum.Organisasi publik adalah tipe organisasi yang bertujuan menghasilkan pelayanan kepada masyarakat, tanpa membedakan status dan kedudukannya. ${ }^{12}$ Pendapat Robbins sebagai berikut: "Perubahan organisasi adalah membuat sesuatu menjadi lain, akan tetapi pemahaman demikian tidak dapat diterima karena perubahan mesti mempunyai tujuan, yaitu terjadi perbaikan atau peningkatan (improvement) kinerja organisasi yang tidak sekedar melakukan perubahan tetapi juga menghasilkan perbaikan."Pengertian perubahan yang mengandung makna ke arah pencapaian tujuan dikemukakan oleh Wood et.al berikut: "bahwa perubahan merupakan upaya terencana, sistematis dan terkendali untuk mengubah lebih dari satu aspek organisasi yakni: (1) tugas, (2) struktur, (3) teknologi, (4) cara berpikir anggota organisasi agar efektif mencapai tujuan organisasi." 13

${ }^{12}$ P. C R. W Backoff Nutt, Strategic Management of public and Third Sector Organizations: A Handbook for Leaders (San Francisco: Jossey-Bass, 1992), h 25 .

${ }^{13}$ Keterampilan Dasar. 


\section{Mirnawati: CAPACITY BUILDING ORGANISASI; .....}

\section{METODE}

Metode penelitian yang digunakan dalam penelitian ini adalah metode penelitian kualitatif dengan tipe penelitian deskriptif.Lokasi penelitian dilakukan di Kelurahan Imopuro Kecamatan Metro Pusat Kota Metro dengan teknik pemilihan informan yang dilakukan secara purposive.Teknik pengumpulan data menggunakan data primer, yamg dijadikan sebagai data primer ialah Lurah dan pegawai Kelurahan Impuro dan data sekunder, yang dijadikan sebagai data sekunder ialah buku-buku serta literature yang berkaitan dengan penelitian. Teknik pemeriksaan keabsahan data menggunakan teknik triangulasi sumber dan triangulasi teknik pengumpulan data.Teknik analisis data terdiri dari reduksi data, penyajian data dan penarikan kesimpulan.

\section{HASIL DAN PEMBAHASAN}

Secara administratif Kelurahan Imopuro termasuk salah satu kelurahan dari 5 kelurahan yang ada di Kecamatan Metro Pusat, sedangkan kelurahan lainnya adalah Kelurahan Metro, Kelurahan Yosomulyo, Kelurahan Hadimulyo Barat, Kelurahan Hadimulyo Timur. Berdasarkan hasil penelitian dapat diketahui bahwa secara umum capasity building organisasi difokuskan pada tingkatan individu/sumber daya manusia, tingkatan organisasi/lembaga dan tingkatan sistem ketatalaksanan di kelurahan Imopuro Kecamatan Metro Pusat Kota Metro dapat dikatakan kurang baik.

\section{Kapasitas Sumber Daya Manusia}

Pengembangan kapasitas sumber daya manusia Kelurahan Imopuro berupa kapasitas pengetahuan, kapasitas keterampilan, kapasitas sikap dan perilaku kerja secara umum cukup baik, kapasitas pendidikan pegawai misalnya yang memiliki minimal ijazah SMA/SLTA. Sebaliknya lulusan sarjana seagian malah kurang memiliki keterampilan. Pelayanan sebagai wujut pelaksanaan visi dan misi kelurahan kepada masyarakat berjalan sebagaimana mestinya, pegawai kelurahan Imopuro sangat berpengalaman karena telah bekerja tahunan bahkan belasan tahun di tempat dan tugas yang sama 
sehingga untuk hal-hal terkecil tidak heran mereka ketahui, oleh karena itu mengarah pada pengetahuan pegawai dapat dikatakan pegawai Kelurahan Imopuro memiliki pengetahuan yang cukup tinggi.

Akan tetapi mengarah pada keterampiran dikatakan kurang karena ketidak mampuan mengoprasikan komputer bagi sebagian pegawai. Tugas pelayanan dan laporan tertutupi dengan kemampuan pegawai lainnya walaupun begitu tetap saja terlaksana. Pelatihan/pendidikan tambahan yang menunjang juga tidak ada. Sikap dan perilaku kerja juga dapat dikatakan kurang baik. Rasa tanggung jawab terhadap pekerjaan sangat kurang, disiplin jam kerja kurang, sehari-hari waktu terbuang percuma untuk mengobrol,10 budaya malu pegawai jarang di indahkan.

\section{Tingkatan Organisasi/Lembaga}

Capacity building organisasi Kelurahan Imopuro yang difokuskan pada tingkatan organisasi organisasi/lembaga adalah dengan kapasitas struktur organisasi, kapasitas anggaran, kapasitas sarana dan prasarana kerja. Capacity dilevel ini secara menyeluruh dikatakan cukup baik. Struktur organisasi dikelurahan Imopuro dikatakan sangat baik karena sudah sesuai dengan Peraturan Daerah Kota Metro Nomor 03 Tahun 2003. Hanya saja komposisi staf dan penempatan tidak sesuai latar belakang pendidikan dan keahlian serta masih kekurangan pegawai yang kompeten.

Kapasitas anggaran kelurahan Imopuro dipandang cukup baik walaupun pendistribusian dana anggaran operasional tidak sepenuhnya tepat sasaran. Sarana dan prasarana juga dinilai kurang baik ini disebabkan fasilitas fisik kantor yang tidak memadai sempit, posisi terpojok, sembunyi, aula dan ruang kerja yang kecil juga sarana komputer dan printer hanya 1 set. Fasilitas kebersihan kelurahan seperti kendaraan pengangkut sampah dalam kondisi kurang baik,

\section{Tingkat Sistem Ketatalaksaan}

Capasity building organisasi Kelurahan Imopuro yang difokuskan pada tingkatan sistem ketatalaksanaan dibagi 3 yaitu 


\section{Mirnawati: CAPACITY BUILDING ORGANISASI;}

kebijakan menyangkut penerapan standar prosedur operasi, kebijakan kepemimpinan, kebijakan menyangkut tupoksi unit kerja secara keseluruhan dikatakan cukup baik.

Pegawai kelurahan Imopuro dalam melaksanakan pekerjaan sangat memperhatikan SOP, akan tetapi terkadang masih mengharapkan pamrih serta cara kerja sering kali menunda pekerjaan dengan alasan urusan diluar kantor sehingga pekerjaan dinomer duakan. kapasitas kepemimpinan lurah dikatakan baik, kemudian untuk kapasitas tupoksi juga dinilai baik secara keseluruhan karena tupoksi dikerjakan dengan baik jika diliat dari hasil, karena pekerjaan di kantor kelurahan Imopuro hampir tidak pernah tidak dilaksanakan hanya saja pekerjaan tidak dilaksanakan oleh pejabat yang mengemban tetapi tertutupi oleh kawan kerja lainnya yang bersedia menyelesaikan.

\section{KESIMPULAN}

Dari hasil penelitian, ada beberapa hal yang perlu dibenahi dan diperbaiki dalam hal:

1. Peningkatan dan perbaikan upaya-upaya capacity building organisasi kelurahan Imopuro pada tingkatan individu/SDM lebih ditingkatkan lagi, seperti peningkatan pengetahuan dan keterampilan pegawai yaitu perlu adanya pengadaan seminar, studi banding atau pelatihan-pelatihan penunjang, pelatihan jabatan dan lainnya serta upaya merubah mainset kerja serta sikap pegawai terhadap tanggung jawab pekerjaan, suasana kekeluargaan dan gotong royong bersikap ikhlas dalam melaksanakan tugas tanpa terfokus pada uang.

2. Peningkatan dan perbaikan upaya-upaya capasity building organisasi kelurahan Imopuro pada tingkatan organisasi/struktur yaitu peningkatan penyediaan kelengkapan sarana dan prasarana, perbaikan kantor terutama ruang kerja, letak dan posisi gedung kantor serta lingkungan kerja yang dibuat lebih nyaman, indah dan aman. 
3. Peningkatan dan perbaikan upaya-upaya capasity building organisasi Kelurahan Imopuro pada tingkatan sistem/ketatalaksanaan yaitu kebijakan pembagian kerja dan penempatan pegawai yang hendaknya disesuaikan dengan latar belakang pendidikan serta kemampuan dan kebutuhan, penambahan personil pegawai disetiap bidang yang dirasakan masih banyak kosong, penegasan sistem kerja dan pembagian kerja yang agar tidak ambiqu di setiap bidang, serta penerapan sistem penerapan standar operasi prosedur sesuai jalur serta kebijakankebijakan lainnya yang dianggap perlu untuk perbaikan sistem di kelurahan.

\section{DAFTAR PUSTAKA}

Aidstar-Two. Organizational Apacity Building Framwork: A Foundation For Stronger, More Sustainable HIV/AIDS Program Organization \& Networks, Mnagement Science for Health, Washington (DC), 2011.

Brown, Lisanne, et. Al. Measuring Capacity Building, Carolina population Center, University of North Carolina, Chapel Hill, 2001.

Grindle, M. S. Getting Good Government Capacity Building In The Public Sector Of Developing Countrie, Boston, MA: Harvard Institute for International Development, 1997.

Irianto, Jusuf. Manajemen SDM Berbasis Kompetensi untuk Aparat Birokrasi. Kalamsasi, Vol. I, No. 2, Jurnal Ilmu Administrasi Negara. FISIP. Unv. Muhammadiyah Sidoarjo

Peraturan daerah Kota Metro nomor 03 tahun 2003.

Mowbray, M. Community Capacity Building or State Opportunism?. Community, Development Journal, 40(3).

Morrison, T. Actionable Learning -A Handbook for Capacity, Building Through Case Based Learning. ADB Institute, 2001.

M. Tambunan, Rudi. Standard Operating Prosedures (SOP), Jakarta: Maiestas Publishing, 2008. 


\section{Mirnawati: CAPACITY BUILDING ORGANISASI;}

Notoatmodjo, S. Promosi Kesehatan dan Ilmu Perilaku, Jakarta: Rineka Cipta, 2007.

Nutt, P. C., Backoff, R. W. Strategic Management of public and Third Sector Organizations: A Handbook for Leaders, San Francisco: Jossey-Bass, 1992.

Robbins. Keterampilan Dasar. Jakarta: PT. Raja Grafindo, 2000.

Soeprapto, Riyadi. Banking Assets and Liability Management, Edsi Ketiga. Penerbit: Fakultas Ekonomi Universitas Indonesia: Jakarta, 2006. 